\title{
Chave de identificação e diagnose dos Histeridae (Insecta: Coleoptera) de interesse forense do Brasil
}

\author{
Nathália G. R. Celli', Fernando W.T. Leivas², Maria Fernanda C. Caneparo' \& Lúcia M. Almeida',3 \\ 1. Laboratório de Sistemática e Bioecologia de Coleoptera (Insecta), Departamento de Zoologia, Universidade Federal do Paraná, Caixa Postal 19030, \\ 81581-980, Curitiba, PR, Brasil. (nathalia.dgr.celli@outlook.com; mafercaneparo@gmail.com) \\ 2. Departamento de Biodiversidade, Universidade Federal do Paraná, Setor Palotina, Rua Pioneiro, 2153, Jardim Dallas, 85950-000, Palotina, PR, Brasil. \\ (fwleivas@gmail.com) \\ 3. Bolsista do Conselho Nacional de Desenvolvimento Científico e Tecnológico. (lalmeida@ufpr.br)
}

\begin{abstract}
Identification key and diagnosis of forensic interest Histeridae (Insecta: Coleoptera) from Brazil. The histerid species are mostly predator and can be found in different environments. Among the groups associated with carcasses, some are reported as relevant in medicolegal entomology. However, the Histeridae taxonomic data is poorly known, especially in the Neotropics. The aim were to elaborate an identification key and provide diagnosis of the Histeridae species with forensic interest from Brazil. Also, the distribution and biological data of the species were added. The following species are recorded in Brazil as important for forensic entomology: Aeletes nicolasi Leivas, 2012; Euspilotus azureus (Sahlberg, 1823); Hister cavifrons Marseul, 1854; Omalodes bifoveolatus Marseul, 1853; Omalodes foveola Erichson, 1834; Omalodes lucidus Erichson, 1834, Operclipygus subterraneus Caterino \& Tishechkin, 2013; Phelister sanguinipennis Marseul, 1853; and Scapomegas auritus Marseul, 1855. This is the first work for forensic studies with Histeridae from Brazil and it can be used at applied forensic entomology.
\end{abstract}

KEYWORDS. Histerids, medicolegal entomology, Neotropical, taxonomy.

RESUMO. As espécies de Histeridae são quase que exclusivamente predadoras e podem ser encontradas em uma grande diversidade de ambientes. Dentre os grupos associados a carcaças, alguns são citados como relevantes na entomologia forense médico-legal. Entretanto, há pouca informação taxonômica para a família, principalmente na Região Neotropical. Desta forma, os objetivos do trabalho foram elaborar uma chave de identificação e caracterizar as espécies de Histeridae de interesse médico-legal no Brasil. Além disso, são apresentadas informações de distribuição geográfica e aspectos biológicos das espécies. As seguintes espécies são registradas como relevantes na entomologia forense no Brasil: Aeletes nicolasi Leivas, 2012; Euspilotus azureus (Sahlberg, 1823); Hister cavifrons Marseul, 1854; Omalodes bifoveolatus Marseul, 1853; Omalodes foveola Erichson, 1834; Omalodes lucidus Erichson, 1834, Operclipygus subterraneus Caterino \& Tishechkin, 2013; Phelister sanguinipennis Marseul, 1853; e Scapomegas auritus Marseul, 1855. Esta contribuição representa a primeira ferramenta para uma melhor identificação dos Histeridae associados a carcaças no Brasil e pode servir como referência e aplicação na entomologia médico-legal.

PALAVRAS-CHAVE. Entomologia médico-legal, histerídeos, Neotropical, taxonomia.

A entomologia forense é uma subárea das ciências forenses na qual o estudo dos insetos é aplicado em procedimentos legais (Oliveira-Costa, 2008). Segundo LORD \& STEVENSON (1986). A entomologia forense é dividida em três categorias: entomologia urbana (que estuda a interação entre entomofauna e o ambiente urbano, envolvendo a presença de insetos que danificam móveis e construções); entomologia de produtos estocados (dedicada a estudar as relações entre os insetos e a infestação de produtos armazenados ou estocados); e a entomologia médico-legal ou médico-criminal (a qual estuda os insetos que são úteis na elucidação de casos com morte). A entomologia médico-legal envolve o estudo de insetos necrófilos que colonizam cadáveres humanos ou carcaças animais (LORD \& STEVENSON, 1986).

Os insetos são os primeiros a encontrar o cadáver e estão presentes em todas as fases de decomposição, pois utilizam este como substrato para desenvolvimento, reprodução e alimentação (CATTS \& GoFF, 1992). As principais ordens que compõem o conjunto de insetos de interesse forense são Diptera (moscas), Coleoptera (besouros), Hymenoptera (vespas, abelhas e formigas) e Lepidoptera (borboletas e mariposas). As duas primeiras se destacam por serem comumente utilizadas na estimativa do tempo de morte, ou intervalo pós-morte (IPM) (MISE et al., 2007; CANEPARO et al., 2012).

Coleoptera possui 387.100 espécies descritas (ZhANG, 2011) e apresenta grande diversidade de hábitos alimentares (MARINONI, 2001). Apesar de existir espécies necrófagas, oportunistas e onívoras, a maioria das de importância forense é predadora (GoFf, 1991). De acordo com Kulshrestha \& SATPATHY (2001), os coleópteros são uma das principais evidências entomológicas para determinação do IPM, baseadas principalmente no padrão de sucessão.

No Brasil, ainda são poucos os estudos que enfocam a fauna de Coleoptera no contexto da entomologia médicolegal. O trabalho de LUEDERWALDT (1911) é o primeiro e um dos estudos mais completos, onde foi registrado mais de 60 espécies de besouros relacionadas a carcaças. Após essa data, alguns outros estudos forenses foram realizados, citando Staphylinidae, Silphidae e Histeridae como as principais famílias de interesse forense (MonTEIRO-FILHO \& Peneireiro, 1987; Carvalho et al., 2000; Carvalho \& LinHARes, 2001; Mise et al., 2007; Mise et al., 2010).

Histeridae apresenta 4.252 espécies descritas 
pertencentes a 391 gêneros, 17 tribos e 11 subfamílias (MAZur, 2011). Na Região Neotropical são conhecidos 139 gêneros e 1.047 espécies (CoSTA, 2000), sendo que destas, 120 gêneros e 449 espécies são registradas para o Brasil (MAZUR, 2011).

Os histerídeos são conhecidos como predadores generalistas que se alimentam de ovos e larvas de Diptera e também podem ser encontrados em associação com outros animais, principalmente com insetos sociais, como formigas e cupins. Com ampla variação de hábitats, podem ocorrer em fezes, fungos, troncos, frutos em decomposição, raízes de árvores, ninhos de aves, tocas de mamíferos ou répteis, vegetação em decomposição e carcaças (LEIVAS et al., 2013).

Dentre os gêneros que apresentam associação com carcaças no Brasil destacam-se Aeletes Horn, 1873, Euspilotus Lewis, 1907, Hister Linnaeus, 1758, Omalodes Dejean, 1833, Operclipygus Marseul, 1870, Phelister Marseul, 1854 e Scapomegas Lacordaire, 1854 (AlmEIDA \& Mise, 2009; Mise et al., 2010; CORRÊA et al., 2012; LeIVAS et al., 2012a,b). Entretanto, grande parte da identificação de Histeridae nos estudos brasileiros de entomologia forense não atinge níveis específicos, pois as poucas informações taxonômicas conhecidas estão dispersas. Além disso, vale ressaltar que a identificação equivocada destas espécies pode acarretar em uma estimativa do IPM errada, uma vez que uso de dados biológicos é dependente da correta identificação (KREITLOW, 2010).

A identificação mais acurada para algumas espécies, famílias e gêneros de coleópteros de interesse médico-legal está restrita a Almeida \& Mise (2009), onde Histeridae e alguns de seus gêneros (Aeletes, Euspilotus, Omalodes, Hister e Phelister) são citados como importantes para os estudos na América do Sul. Em função da carência na identificação correta das espécies, bem como sua importância na entomologia forense, o objetivo deste trabalho foi elaborar uma chave de identificação, acrescentar caracteres diagnósticos, ilustrações e informações atualizadas da distribuição geográfica dos táxons de Histeridae de interesse médico-legal para o Brasil.

\section{MATERIAL E MÉTODOS}

As espécies estudadas foram selecionadas após o levantamento bibliográfico e de acordo com sua distribuição (Brasil) e importância para entomologia médico-legal. A atualização dos nomes científicos foi feita com base no catálogo de MAzUr (2011). Os exemplares depositados na Coleção Entomológica Pe. Jesus Santiago Moure (DZUP) foram a base dos estudos morfológicos e para a complementação das informações de dados biológicos.

A chave dicotômica e as diagnoses foram baseadas nos caracteres levantados no estudo morfológico e em Arriagada (1986), MAZUr (2001) e AbAllay et al. (2013) e a terminologia adotada seguiu LeIVAs et al. (2015).

Para distribuição geográfica das espécies, utilizouse os seguintes autores: Mise et al., 2007; SouzA et al., 2008; Mise et al., 2010; Correa et al., 2012; LeIVAS et al., 2012a,b, 2013; Silva \& SAntos, 2012; Mayer \& VASCONCELOS, 2013.

As fases de decomposição não apresentam consenso na literatura, diversos autores a classificam em número variado dependendo das características físico-químicas da carcaça (MÉGnin, 1894; Bornemissza, 1957; PAYNe, 1965; Archer et al., 2005). Com a finalidade de discutir a ocorrência das espécies estudadas, foi elaborado um padrão de distinção das fases de decomposição (inicial, mediana e final). A fase inicial equivale à putrefação; a mediana à putrefação escura, fermentação e fermentação butírica; e a final corresponde à seca e deterioração (Fig. 1).

\section{RESULTADOS}

No total, nove espécies de três subfamílias são registradas em estudos de entomologia médico-legal no Brasil: Aeletes nicolasi Leivas, 2012 (Abraeinae), Euspilotus (Hesperosaprinus) azureus (Sahlberg, 1823) (Saprininae), Hister cavifrons Marseul, 1854, Omalodes (Omalodes) bifoveolatus Marseul, 1853, Omalodes (O.) foveola Erichson, 1834, Omalodes (O.) lucidus Erichson, 1834, Operclipygus subterraneus Caterino \& Tishechkin, 2013, Phelister sanguinipennis Marseul, 1853 e Scapomegas auritus Marseul, 1855 (Histerinae).

Os histerídeos de interesse médico-legal foram amostrados em estudos forenses com carcaças de coelho e suína. Euspilotus azureus e Omalodes foveola foram registradas em todas as fases de decomposição, enquanto

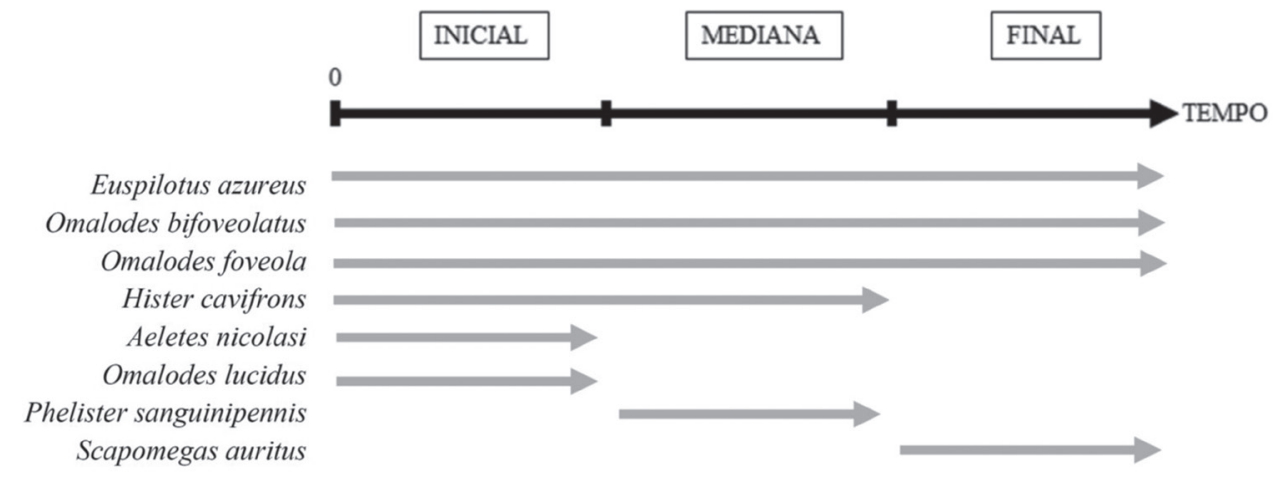

Fig 1. Representação esquemática dos Histeridae de interesse médico-legal do Brasil no momento de ocorrência na carcaça ao longo da decomposição. 
Tab. I. Espécies de Histeridae de interesse médico-legal do Brasil, relacionadas com o substrato e as fases de decomposição.

\begin{tabular}{|c|c|c|c|}
\hline Espécie & Substrato & Fase de decomposição & Referência \\
\hline Aeletes nicolasi & Carcaça de coelho & Seca; putrefação & LEIVAS et al. (2012b) \\
\hline \multirow{4}{*}{ Euspilotus azureus } & Carcaça suína & Todas as fases & Mise et al. (2010) \\
\hline & Carcaça suína & $\begin{array}{l}\text { Putrefação; putrefação escura; } \\
\text { fermentação butírica }\end{array}$ & Mise et al. (2007) \\
\hline & Carcaça de coelho & Putrefação escura; seca & SiLVA \& SANTOS (2012) \\
\hline & Carcaça de coelho & Fermentação; deterioração. & SouzA et al. (2008) \\
\hline $\begin{array}{l}\text { Hister cavifrons } \\
\text { (citado como Hister sp. em Mise et al., 2007) }\end{array}$ & Carcaça suína & $\begin{array}{l}\text { Putrefação; putrefação escura; } \\
\text { fermentação butírica }\end{array}$ & MisE et al. (2007) \\
\hline Omalodes bifoveolatus & Carcaça suína & $\begin{array}{c}\text { Putrefação; putrefação escura; } \\
\text { seca }\end{array}$ & MisE et al. (2010) \\
\hline \multirow{2}{*}{ Omalodes foveola } & Carcaça suína & Putrefação & Mise et al. (2010) \\
\hline & Carcaça suína & Todas as fases & MAYER \& VASCONCELOS (2013) \\
\hline Omalodes lucidus & Carcaça suína & Putrefação & Mise et al. (2010) \\
\hline Operclipygus subterraneus & Carcaça de coelho enterrada & - & CORRÊA et al. (2012) \\
\hline Phelister sanguinipennis & Carcaça suína & Fermentação butírica & Mise et al. (2010) \\
\hline Scapomegas auritus & Carcaça suína & Seca & Mise et al. (2010) \\
\hline
\end{tabular}

as demais espécies são exclusivas de uma ou mais fases da decomposição cadavérica (Tab. I).

\section{Chave de identificação para os gêneros de Histeridae} de interesse médico-legal registrados no Brasil

1. Labro com cerdas; prosterno com cavidade lateral para recepção do funículo da antena (Fig. 7) ..................... 2

1'. Labro sem cerdas; prosterno sem cavidade lateral para recepção do funículo da antena, projeção lateral do lobo prosternal cobrindo totalmente ou parcialmente a cavidade da clava antenal (Fig. 14) .. 3

2. Clava antenal, quando em repouso, situada lateralmente ao prosterno, próximo a quilha prosternal; prosterno, estria carenal unida com a estria lateral anteriormente $\mathrm{e}$ terminando na fóvea pré-apical (Fig. 7); estrias dorsais dos élitros presentes (Fig. 6); escutelo visível

Euspilotus Lewis

2'. Clava antenal, quando em repouso, ao lado do hipômero; estrias dorsais dos élitros ausentes; escutelo não visível e estria ante-escutelar presente (Fig. 4); estria marginal do epistoma presente Aeletes Horn

3. Margem externa das tíbias posteriores com duas séries de espinhos (Fig. 12) Hister Linnaeus

3'. Margem externa das tíbias posteriores com uma série de espinhos (Fig. 15) 4

4. Cavidade tarsal da tíbia anterior sinuosa (Fig. 21) ...... Omalodes Dejean

4'. Cavidade tarsal da tíbia anterior reta 5

5. Quilha prosternal com estria carenal triangular (Fig. 23) e pigídio com sulco ou estria marginal (Fig. 24) .... Operclipygus Marseul

5'. Sem a combinação dos caracteres acima ... 6

6. Antenas com escapo alargado na base e no ápice (Figs 27, 29); ápice dos élitros com depressão na região das três primeiras estrias dorsais (Fig. 27)

Scapomegas Lacordaire

6'. Antenas com escapo afilado na base; ápice dos élitros sem depressão Phelister Marseul

\section{Aeletes nicolasi Leivas, 2012}

(Figs 4, 5)

Diagnose. Comprimento: 0,74-0,84 mm; largura: 0,30-0,50 mm. Corpo oval, convexo (Fig. 4), marrom e brilhante, coberto dorsalmente e ventralmente por pequenas cerdas. Cabeça com estria marginal do epistoma completa. Pronoto com estria ante-escutelar arqueada e representada por uma série de pontos (Fig. 4). Prosterno, quilha prosternal achatada e mais larga na região anterior do que na região posterior (Fig. 5). Mesosterno, região discal com sulcos longitudinais, mais longos na região central do disco (Fig. 5). Metasterno, estrias pós-mesocoxais presentes; placa pós-mesocoxal rugosa (Fig. 5). Élitros pontuados e com rugosidade ao longo da região sutural; estrias dorsais ausentes (Fig. 4). Metatarso, tarsômero basal mais curto que os próximos três tarsômeros juntos. Pigídio mais longo que o propigídio, região anterior com rugosidade; estria marginal completa.

Comentários: maiores informações taxonômicas biológicas e de distribuição geográfica podem ser encontradas em LeIvas et al. (2012b).

Distribuição geográfica no Brasil: Paraná.

Fase de decomposição: inicial e final (Fig. 1).

\section{Euspilotus (Hesperosaprinus) azureus (Sahlberg, 1823)}

$$
\text { (Figs 6-8) }
$$

Diagnose. Comprimento: 2,9-5,5 mm; largura: 2,54,7 mm. Corpo oval, convexo (Fig. 6), azul metálico ou preto. Cabeça finamente pontuada; estria frontal ausente; região anterior da fronte com uma fóvea fraca (Fig. 8). Pronoto com pontuação forte lateralmente e depressão próxima aos ângulos anteriores; estria marginal completa e muito próxima à margem lateral; hipômero glabro. Prosterno com estria lateral marginal completa; quilha prosternal estreita (Fig. 7) com estrias carenais presentes e unidas apicalmente à estria lateral marginal. Mesosterno 


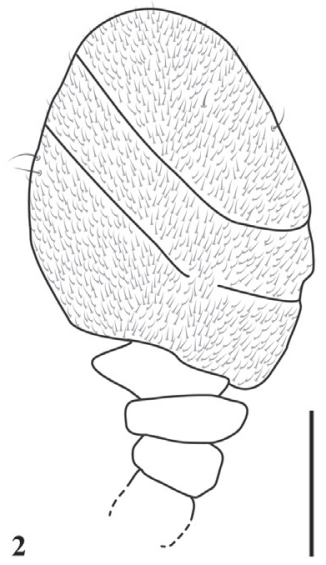

3

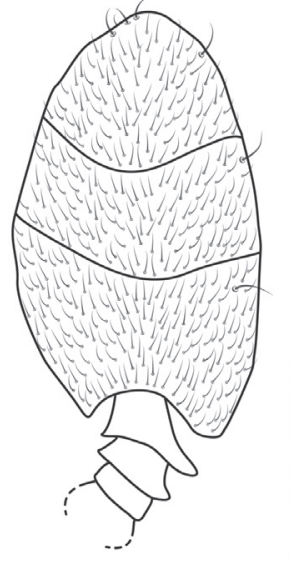

Figs 2, 3. Antenas; 2, Omalodes bifoveolatus Marseul, 1853, pseudosuturas da clava antenal em "V"; 3, Scapomegas auritus Marseul, 1855, pseudosuturas da clava antenal curvadas. Escalas: 0,25 mm.

com estria marginal completa e estria discal ausente; sutura meso-metasternal presente e com uma série de pontos sobre a mesma. Metasterno, estria pós-mesocoxal presente; estria lateral metasternal oblíqua (Fig. 7). Élitros, região anterior com fina e esparsa pontuação; $1^{\mathrm{a}} \mathrm{e} 2^{\mathrm{a}}$ estrias dorsais completas; $3^{\mathrm{a}}$ ausente ou rudimentar; $4^{\mathrm{a}}$ estria dorsal completa na metade anterior e conectada basalmente com a estria sutural (Fig. 6); estria apical presente da margem externa até a metade do élitro. Propigídio com pontuação densa similar ao pigídio; pigídio com estria marginal completa (Figs 6, 7).

Comentários: maiores informações taxonômicas, biológicas e distribuição geográfica podem ser encontradas em Degallier et al. (2012) e Aballay et al. (2013).
Distribuição geográfica no Brasil: Amazonas, Minas Gerais, Paraná, Rio Grande do Sul.

Fase de decomposição: inicial, mediana e final (Fig. 1).

\section{Hister cavifrons Marseul, 1854}

(Figs 9-12)

Diagnose. Comprimento: 4,4-5,2 mm; largura: 4,3$5,1 \mathrm{~mm}$. Corpo convexo, oval levemente alongado, negro e brilhante (Fig. 9). Cabeça finamente pontuada; fronte deprimida anteriormente e estria frontal completa (Fig. 11). Pronoto finamente pontuado; estria marginal interrompida atrás da cabeça; estria lateral externa não alcança a base do pronoto, interrompida atrás da cabeça; estria lateral interna completa (Fig. 9). Prosterno, quilha prosternal estreita (Fig. 10) e estrias carenais ausentes. Mesosterno com sutura meso-metasternal completa (Fig. 10). Metasterno, estria pós-mesocoxal presente; estria lateral metasternal curvada para fora. Élitros, estria subumeral interna presente na metade posterior; estria subumeral externa pouco desenvolvida e conectada na região mediana do élitro com a estria subumeral interna; $1^{\mathrm{a}}-4^{\mathrm{a}}$ estrias dorsais bem desenvolvidas, $5^{\text {a }}$ estria dorsal presente na metade posterior do élitro; estria sutural ausente na margem anterior. Propigídio com fóveas fracas e pontuação um pouco mais grossa nas laterais. Pigídio lateralmente com pontuação um pouco mais grossa.

Comentários: a depressão na fronte possui intensidade variável. A $5^{\mathrm{a}}$ estria dorsal do élitro pode ocupar toda metade posterior ou estar marcada apenas apicalmente. Maiores informações taxonômicas, biológicas
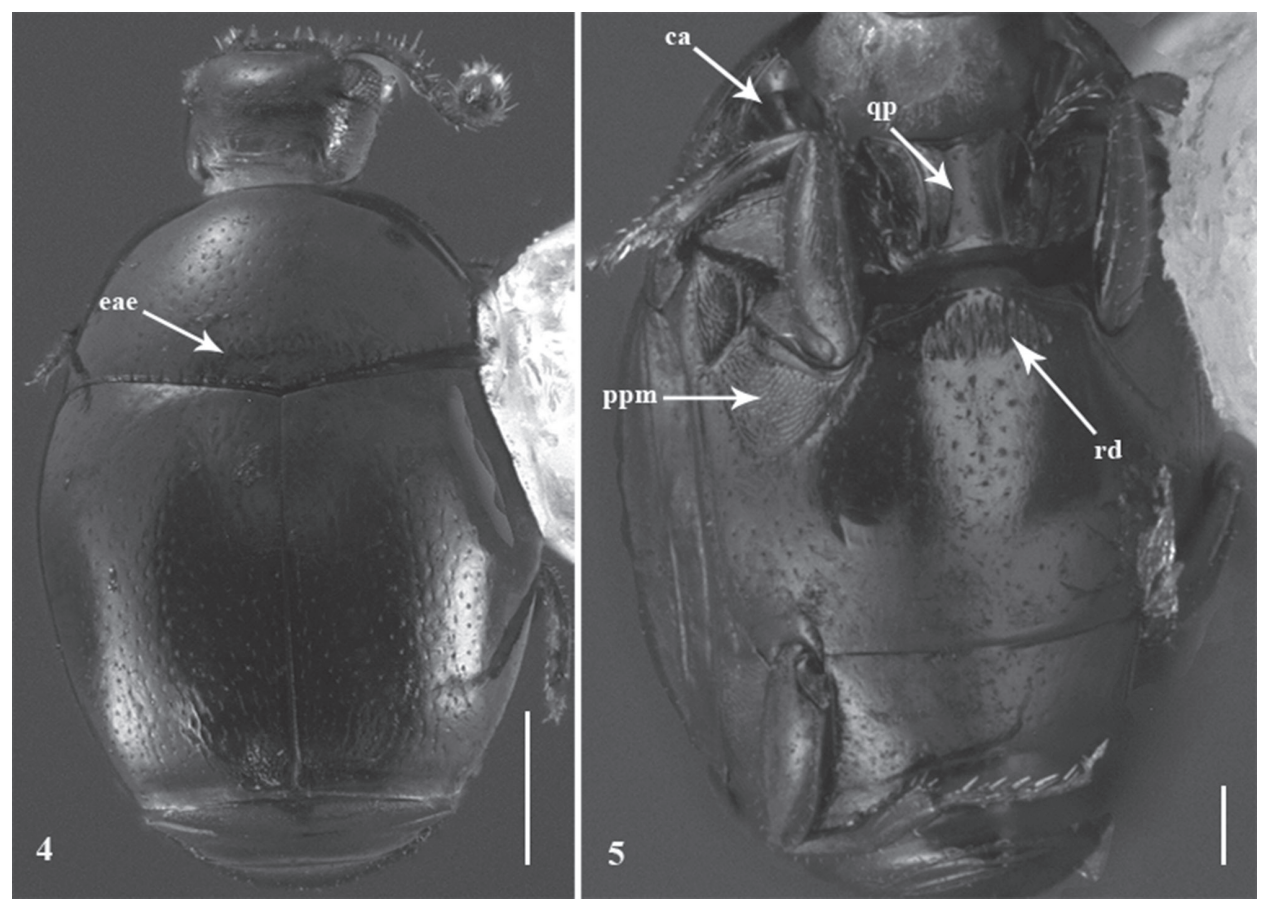

Figs 4, 5. Aeletes nicolasi Leivas, 2012: 4, vista dorsal, estria ante-escutelar do pronoto (eae); 5, vista ventral, cavidade para recepção da clava da antena (ca), quilha prosternal (qp), placa pós-mesocoxal (ppm), região discal do metasterno (rd). Escalas 4: 0,25 mm; 5: 0,10 mm. 


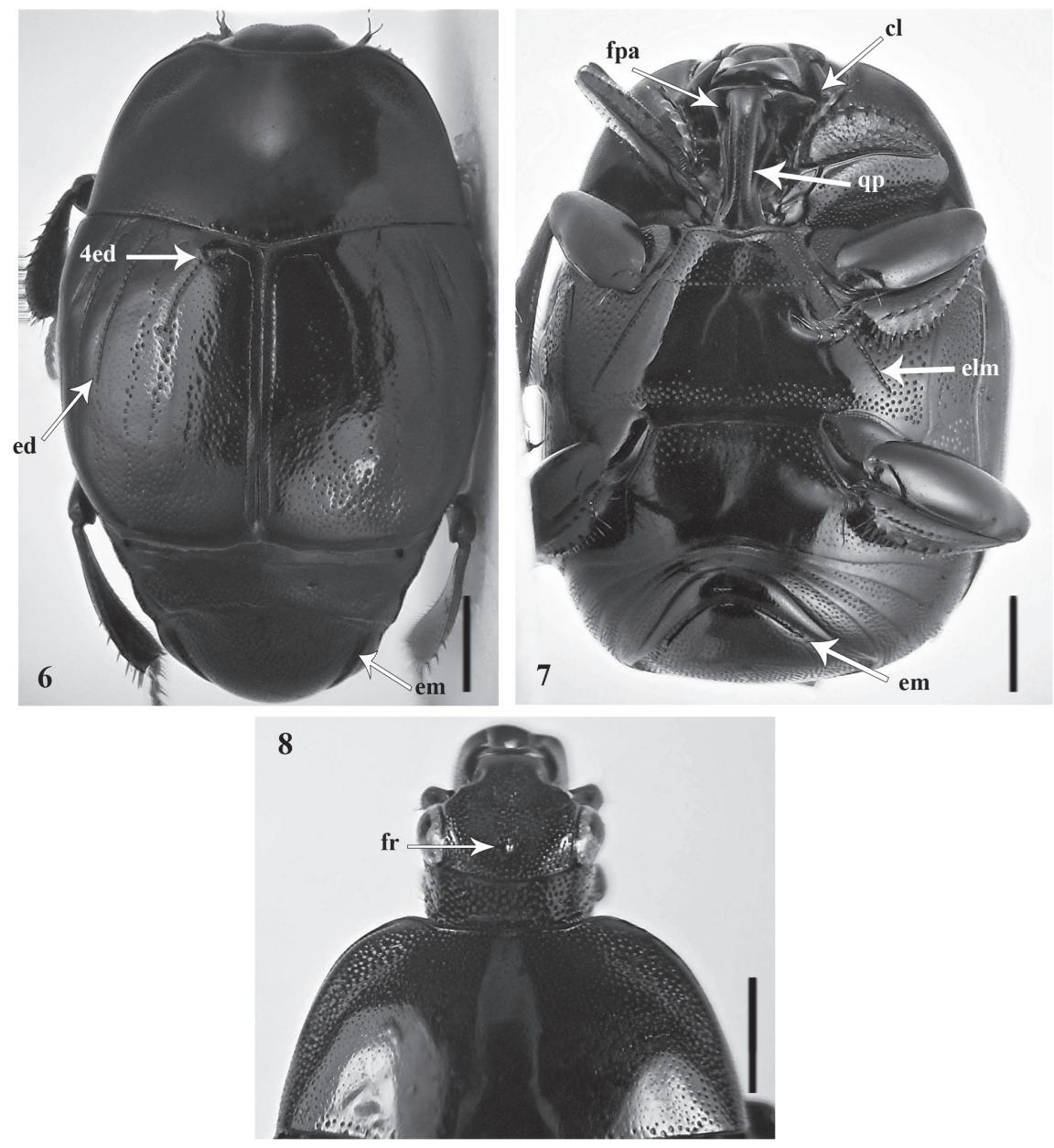

Figs 6-8. Euspilotus azureus (Sahlberg, 1823): 6, vista dorsal, $4^{\mathrm{a}}$ estria dorsal do élitro (4ed), estrias dorsais do élitro (ed), pigídio com estria marginal (em); 7, vista ventral, fóvea pré-apical do prosterno (fpa), cavidade lateral para a recepção do funículo da antena (cl), quilha prosternal (qp), estria lateral metasternal (elm), pigídio com estria marginal (em); 8, vista dorsal, fóvea da fronte (fr). Escalas: $1 \mathrm{~mm}$.

e distribuição geográfica sobre o gênero e a espécie podem ser encontradas em CATERINO (1999a, b, 2002).

Distribuição geográfica no Brasil: Piauí, Pernambuco, Bahia, Minas Gerais, Espírito Santo, Rio de Janeiro e Paraná.

Fase de decomposição: inicial e mediana (Fig. 1).

Chave para as espécies de Omalodes (Omalodes) de interesse médico-legal registradas no Brasil

1. Propigídio com duas fóveas na região posterior, pontuação grossa bem marcada nas laterais e com uma área mais ou menos lisa no centro do disco (Fig. 18) .. Omalodes (O.) foveola Erichson

1'. Propigídio sem fóveas na região posterior e com pontuação grossa dispersa

2. Pronoto com fóvea mediana nas laterais (Fig. 13), margens laterais com pontuação grossa dispersa

Omalodes (O.) bifoveolatus Marseul

2'. Pronoto sem fóvea, margens laterais sem pontuação grossa, apenas um pouco mais diferenciada do que o restante da superfície (Fig. 19)

Omalodes (O.) lucidus Erichson

\section{Omalodes (Omalodes) bifoveolatus Marseul, 1853}

(Figs 2, 13-15)

Diagnose. Comprimento: 5,8-7,1 mm; largura: 4,9-6,4 mm. Corpo arredondado, um pouco alongado, negro, brilhante e finamente pontuado (Fig. 13). Cabeça, fronte com uma fóvea mediana; sutura fronto-clipeal marcada nas laterais e estria frontal completa. Antenas com pseudosuturas da clava em "V" (Fig. 2). Pronoto com pontuação grossa nas laterais; presença de uma fóvea mediana em cada lateral; estria marginal interrompida atrás da cabeça; estria lateral externa completa (Fig. 13). Prosterno, estria marginal do lobo prosternal completa; quilha prosternal com pontuação fina, levemente achatada na região posterior, estrias carenais geralmente presentes e longas (Fig. 14). Mesosterno com pontuação grossa nas laterais; estria marginal interrompida na região mediana. Metasterno, estria lateral curvada para fora em direção à sutura metasternal-mesepimeral. Élitros, estria subumeral externa presente apenas no terço posterior; estria subumeral interna geralmente ausente; $1^{\mathrm{a}}$ estria dorsal completa; $2^{\mathrm{a}}$ 
estria dorsal não iniciando na margem anterior; $3^{\mathrm{a}}$ estria dorsal fracamente marcada e presente na metade anterior do élitro; $4^{\mathrm{a}}$ e $5^{\mathrm{a}}$ estrias dorsais ausentes; estria sutural usualmente presente e estria apical ausente. Propigídio com pontuação grossa e dispersa, quase ausente na região anterocentral; pigídio completamente coberto com pontuação grossa (Fig. 14).

Comentários: a estria carenal pode estar reduzida ou ausente em algumas populações. Propigídio pode apresentar fóveas leves nas laterais posteriores.

Distribuição geográfica no Brasil: Acre, Rondônia, Amapá, Amazonas, Pará e Mato Grosso.

Fase de decomposição: inicial, mediana e final (Fig. 1).

\section{Omalodes (Omalodes) foveola Erichson, 1834}

(Figs 2, 16-18)

Diagnose. Comprimento: 5,2-6,2 mm; largura: 4-5,1 mm. Corpo arredondado, convexo, negro, brilhante e finamente pontuado (Fig. 16). Cabeça, fronte com sulco mediano; sutura fronto-clipeal marcada nas laterais e estria frontal interrompida no ápice. Antenas com pseudosuturas da clava em "V" (Fig. 2). Pronoto com pontuação grossa nas laterais; estria marginal interrompida atrás da cabeça; estria lateral externa completa (Fig. 16). Prosterno, estria marginal do lobo prosternal completa; quilha prosternal achatada, com pontuação fina (Fig. 17) e estrias carenais ausentes. Mesosterno geralmente com pontuação fina; estria marginal interrompida na região mediana (Fig. 17). Metasterno, estria lateral completa curvada para fora em direção à sutura metasternal-mesepimeral (Fig. 17). Élitros, estria subumeral externa presente no terço posterior; estria subumeral interna variável; $1^{\mathrm{a}}$ estria dorsal completa; $2^{\mathrm{a}}$ estria dorsal não iniciando na margem anterior; $3^{\mathrm{a}}$ estria dorsal fracamente marcada e presente na metade anterior; $4^{\mathrm{a}}$ e $5^{\mathrm{a}}$ estrias dorsais e estria sutural usualmente ausente; estria apical ausente. Propigídio com pontuação grossa nas laterais com uma área quase lisa na região antero-central, presença de duas fóveas na região posterior; pigídio com pontuação grossa sobre toda superfície (Fig. 18).

Comentários: o mesosterno pode possuir poucos pontos nos ângulos da estria marginal. A estria subumeral interna pode estar presente.

Distribuição geográfica no Brasil: Acre, Rondônia, Amapá, Amazonas, Pará, Piauí, Distrito Federal, Mato Grosso, Ceará, Pernambuco, Bahia, Espírito Santo, Minas Gerais, Rio de Janeiro, São Paulo, Paraná, Santa Catarina e Rio Grande do Sul.

Fase de decomposição: inicial, mediana e final (Fig. 1).

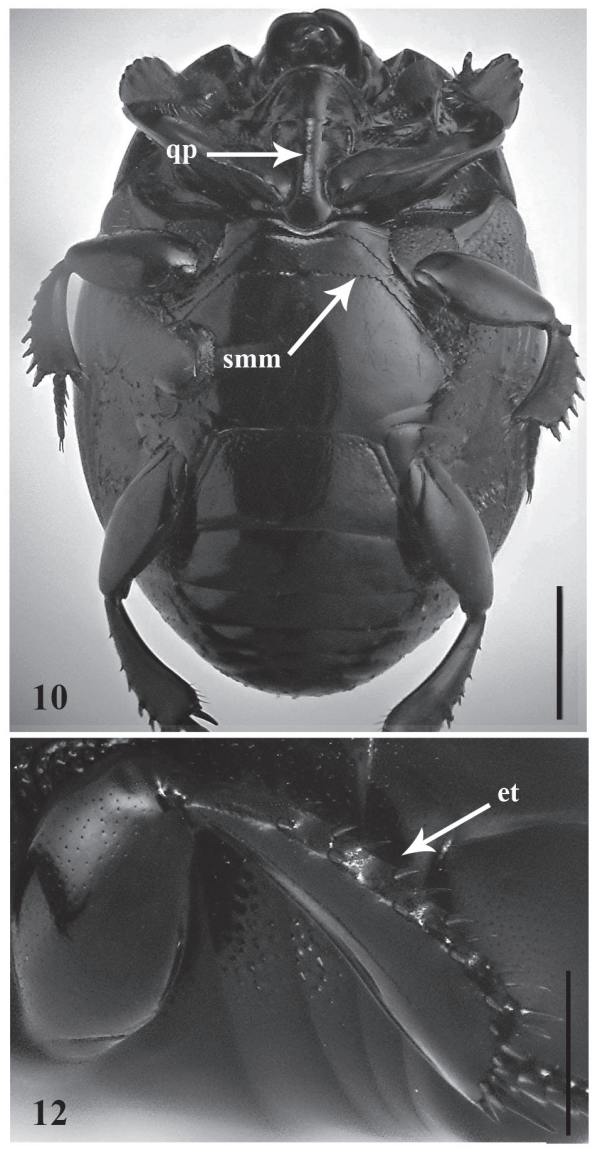

Figs 9-12. Hister cavifrons Marseul, 1854: 9, vista dorsal, estria lateral interna do pronoto (eli); 10, vista ventral, quilha prosternal (qp), sutura meso-metasternal (smm); 11, vista frontal, fronte deprimida (fr), estria frontal (ef); 12, séries de espinhos da margem externa da tíbia posterior (et). Escalas 9-11: $1 \mathrm{~mm} ; 12: 0,5 \mathrm{~mm}$. 


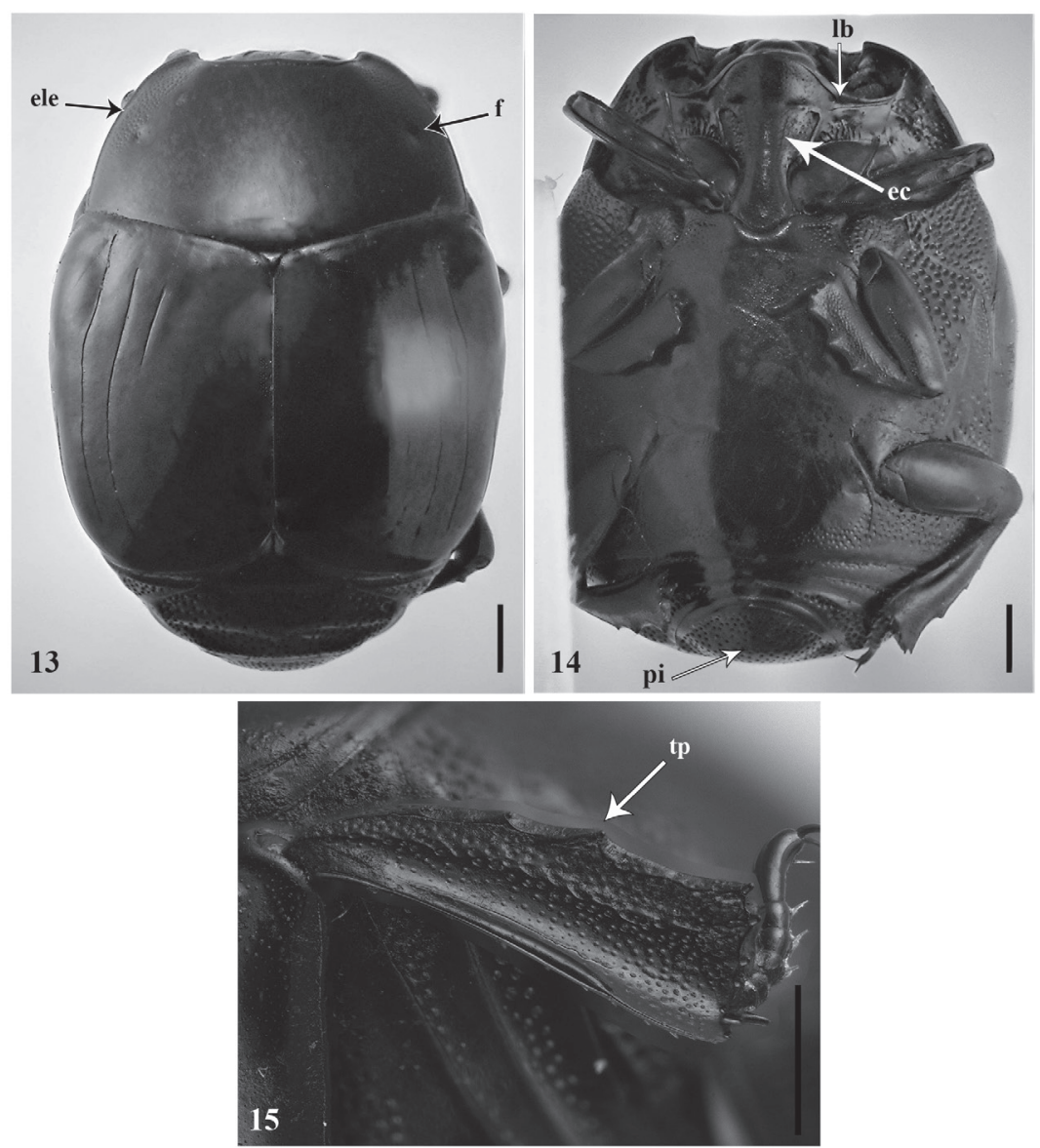

Figs 13-15. Omalodes bifoveolatus Marseul, 1853: 13, vista dorsal, pronoto com estria lateral externa (ele); fóvea lateral (f); 14, vista ventral, estria carenal do prosterno (ec), projeção lateral do lóbulo prosternal (lb), pigídio (pi); 15, série de espinhos da margem externa da tíbia posterior (tp). Escalas 13, 14: $1 \mathrm{~mm}$; 15: 0,5 mm.

\section{Omalodes (Omalodes) lucidus Erichson, 1834}

(Figs 2, 19-21)

Diagnose. Comprimento: 5,4-6,8 mm; largura: 4,2$5,6 \mathrm{~mm}$. Corpo arredondado, convexo, negro, brilhante e finamente pontuado (Fig. 19). Cabeça, fronte com sulco mediano; sutura fronto-clipeal marcada nas laterais; estria frontal interrompida no ápice. Antenas com pseudosuturas da clava em "V" (Fig. 2). Pronoto com pontuação fina nas laterais; estria marginal interrompida atrás da cabeça; estria lateral externa completa (Fig. 19). Prosterno, estria marginal do lobo prosternal completa; quilha prosternal levemente achatada, com pontuação usualmente fina (Fig. 20) e estria carenal variável. Mesosterno geralmente com pontuação grossa nas laterais; estria marginal interrompida na região mediana. Metasterno com estria lateral completa curvada para fora em direção à sutura metasternal-mesepimeral. Élitros, estria subumeral externa presente apenas em um terço posterior; estria subumeral interna ausente; $1^{\text {a }}$ estria dorsal completa e mais fina na metade posterior; $2^{\mathrm{a}}$ estria dorsal não iniciando na margem anterior e mais curta que a primeira dorsal; $3^{\mathrm{a}}$ estria dorsal fina e presente na metade anterior; $4^{\mathrm{a}}$ e $5^{\mathrm{a}}$ estrias dorsais, e estria sutural usualmente ausentes; estria apical ausente; ápice dos élitros com alguns pontos entre a $3^{\mathrm{a}}$ estria dorsal e a sutural (Fig. 19). Propigídio com pontuação grossa e dispersa; superfície do pigídio com pontuação grossa (Fig. 20).

Comentários: a estria carenal da quilha prosternal pode estar presente ou ausente; quando presente, a pontuação mediana da quilha prosternal geralmente é grossa.

Distribuição geográfica no Brasil: Acre, Rondônia Amapá, Amazonas, Maranhão, Pará Ceará e Espírito Santo. Fase de decomposição: inicial (Fig. 1).

\section{Operclipygus subterraneus Caterino \& Tishechkin, 2013}

(Figs 22-24)

Diagnose. Comprimento: $1,59-1,65 \mathrm{~mm}$; largura: 1,31-1,35 mm. Corpo subquadrado, pouco convexo (Fig. 22) e acobreado. Cabeça finamente pontuada; sutura frontoclipeal ausente; estria frontal completa. Pronoto com pontuação grossa e esparsa lateralmente; impressão anteescutelar linear e subigual ao comprimento do escutelo; estria marginal interrompida atrás da cabeça; estria lateral externa interrompida atrás dos olhos e continuada entre os olhos, com suas extremidades curvas para a região central; estria lateral interna ausente. Prosterno, estria marginal do 


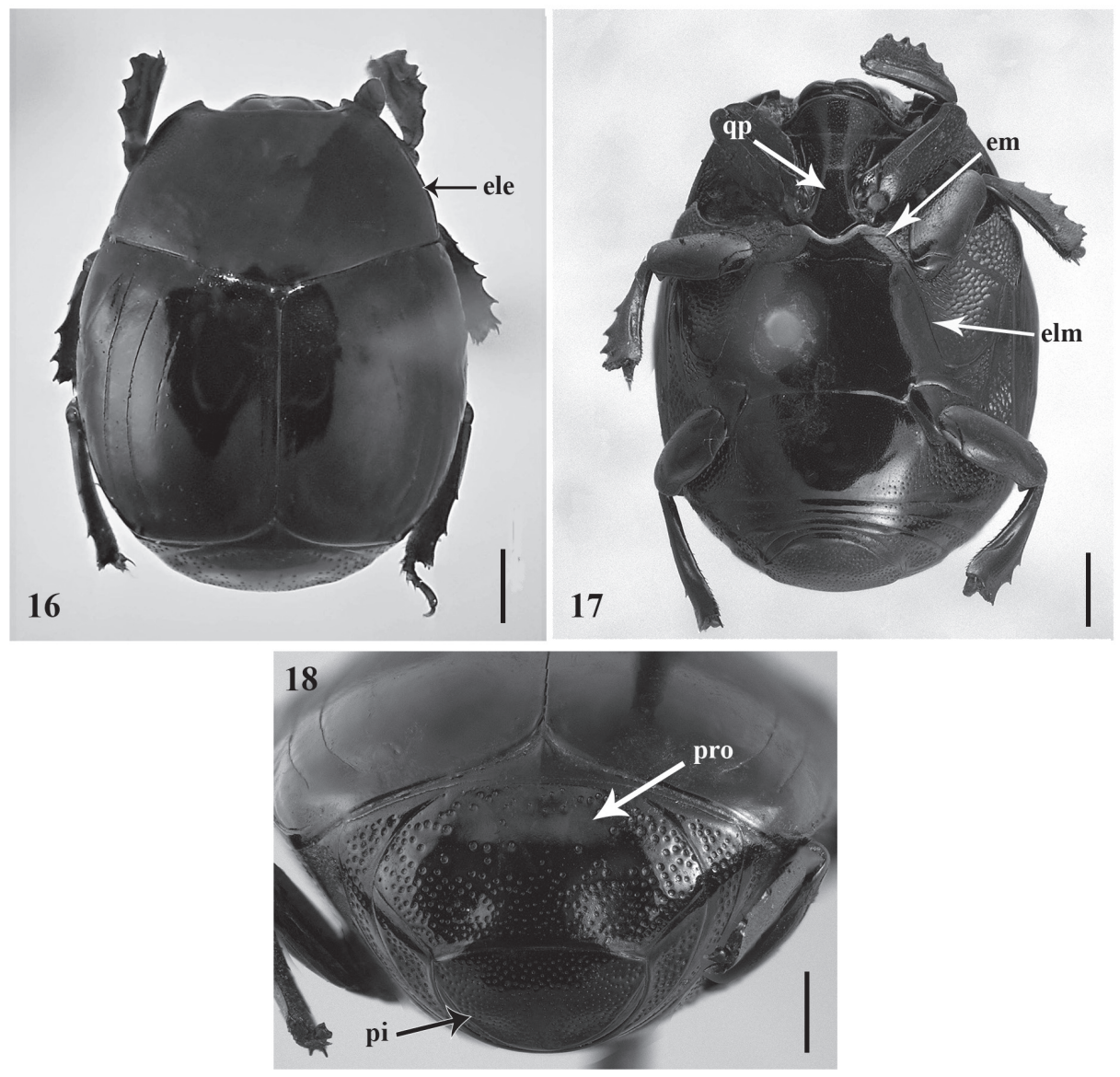

Figs 16-18. Omalodes foveola Erichson, 1834: 16, vista dorsal, pronoto com estria lateral externa (ele); 17, vista ventral, quilha prosternal (qp), estria marginal do mesosterno (em), estria lateral metasternal (elm); 18, vista posterior, propigídio (pro) e pigídio (pi). Escalas 16, $17: 1 \mathrm{~mm}$; 18: 0,5 mm.

lobo prosternal completa; quilha prosternal estreita; estria carenal triangular (Fig. 23). Mesosterno com pontuação fina no disco; margem anterior emarginada; estria marginal completa; estria discal presente (Fig. 23). Metasterno, estria pós-mesocoxal presente; estria lateral oblíqua. Élitros, estria subumeral externa na metade posterior; estria subumeral interna ausente; $1^{\mathrm{a}}-4^{\mathrm{a}}$ estrias dorsais bem desenvolvidas, $5^{\text {a }}$ estria dorsal na metade posterior; estria sutural nos dois terços posteriores (Fig. 22); estria apical ausente. Propigídio com pontuação grossa e dispersa separada por um pouco menos que o diâmetro dos pontos. Pigídio com pontuação em geral fina e com pontos grossos dispersos; estria marginal presente (Fig. 24).

Comentários: maiores informações sobre o gênero e as espécies que ocorrem no Brasil: CorrêA et al. (2012) e CATERino \& Tishechinin (2013).

Distribuição geográfica no Brasil: Minas Gerais, Rio de Janeiro, São Paulo, Paraná e Santa Catarina.

Fase de decomposição: não relatado na literatura.

\section{Phelister sanguinipennis Marseul, 1853}

(Figs 25, 26)

Diagnose. Comprimento: 2,50 mm; largura: 1,30 $\mathrm{mm}$. Corpo ligeiramente convexo (Fig. 25) e avermelhado, com coloração alaranjada nos ângulos anteriores e nas laterais dos élitros. Cabeça finamente pontuada; sutura fronto-clipeal ausente; estria frontal interrompida no centro da fronte (Fig. 25). Pronoto com poucos pontos grossos na região latero-central; estria marginal muito próxima à borda, presente na margem anterior e nos ângulos; estria lateral externa completa; estria lateral interna crenulada e marcada lateralmente (Fig. 25). Prosterno, estria marginal do lobo prosternal completa; quilha prosternal larga com pontuação fina (Fig. 26) e estrias carenais ausentes. Mesosterno sem pontuação; estria marginal completa; estria discal ausente. Metasterno, estria pós-mesocoxal presente; estria lateral curta e obliqua (Fig. 26). Élitros com estria subumeral externa presente na metade posterior; estria subumeral interna ausente; estrias dorsais crenuladas; $1^{\mathrm{a}}$ estria dorsal completa; $2^{\mathrm{a}}$ estria dorsal presente em dois terços posteriores; $3^{\mathrm{a}}$ estria dorsal completa, mais fina na metade anterior e não crenulada; $4^{\mathrm{a}}$ e $5^{\mathrm{a}}$ estrias dorsais na metade posterior; estria sutural um pouco além da metade posterior; estria apical ausente. Propigídio com pontuação densa e grossa e fóveas nas laterais; pigídio com pontuação similar ao propigídio e estria marginal ausente (Fig. 25).

Distribuição geográfica no Brasil: Amazonas. Fase de decomposição: mediana (Fig. 1). 


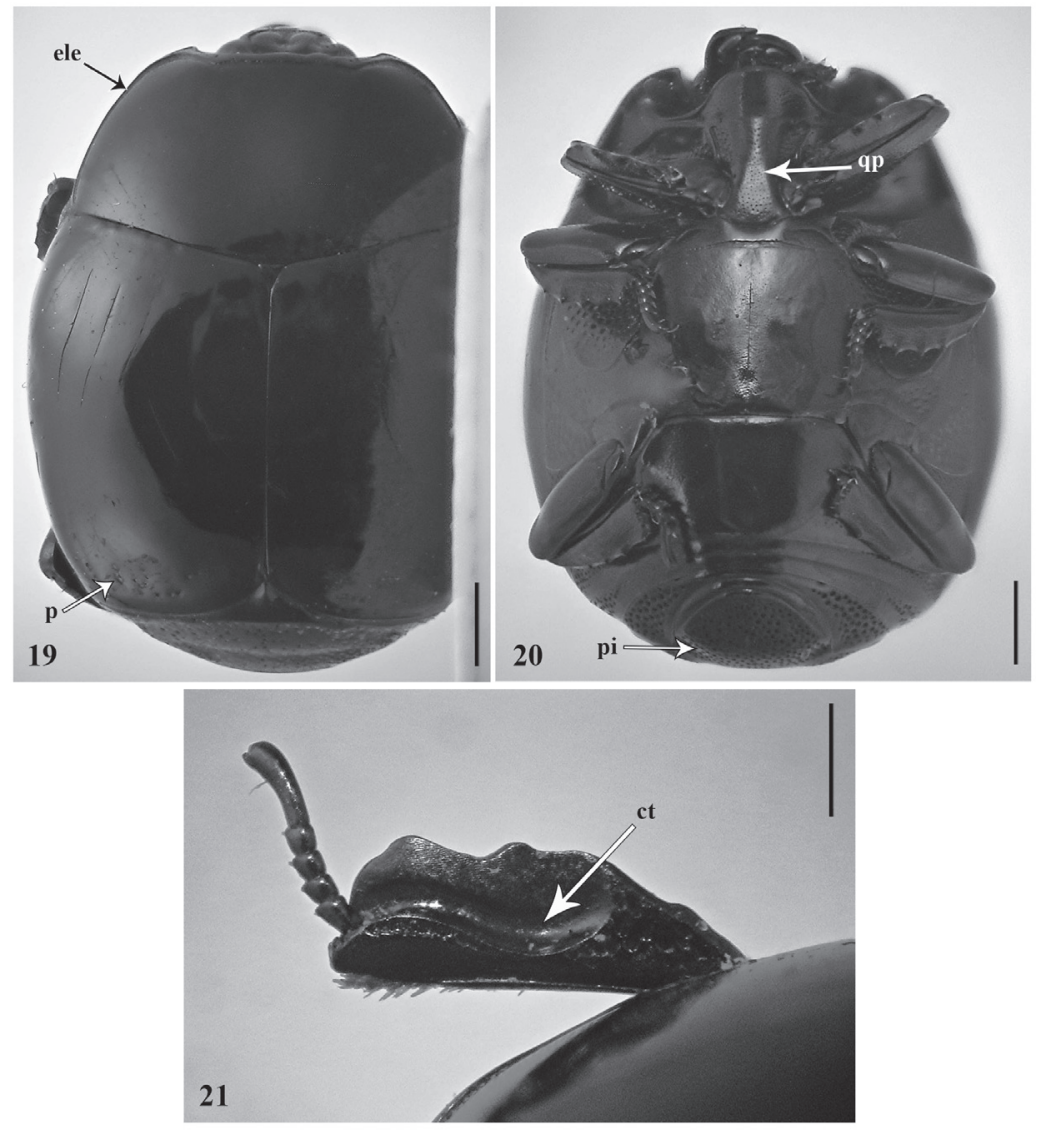

Figs 19-21. Omalodes lucidus Erichson, 1834: 19, vista dorsal, pronoto com estria lateral externa (ele), pontuação no ápice dos élitros (p); 20, vista ventral, quilha prosternal (qp), pigídio (pi); 21, cavidade tarsal da tíbia anterior sinuosa(ct). Escalas 19, 20:1 mm; $21: 0,5 \mathrm{~mm}$.

\section{Scapomegas auritus Marseul, 1855}

(Figs 3, 27-29)

Diagnose. Comprimento: 3,4-4,83 mm; largura: 3,12-4,08 mm. Corpo oval e fortemente convexo (Fig. 27); negro e brilhante, algumas vezes com reflexo azul metálico. Cabeça finamente pontuada; estria frontal rudimentar na região posterior (Fig. 29). Antenas com pseudosuturas da clava curvadas (Fig. 3). Pronoto, estria marginal interrompida atrás da cabeça; estria lateral externa completa. Prosterno com quilha prosternal larga e achatada e estrias carenais convergentes anteriomente (Fig. 28). Mesosterno, estria marginal presente somente nos ângulos anteriores. Metasterno, estria pós-mesocoxal geralmente presente; estria lateral curvada para fora. Élitros, estria subumeral externa presente na metade posterior; estria sub-humeral interna variável; $1^{\mathrm{a}}$ estria dorsal completa; $2^{\mathrm{a}}$ estria dorsal variável; $3^{\mathrm{a}}-5^{\mathrm{a}}$ estrias dorsais curtas e presentes na margem posterior; estria sutural completa (Fig. 27). Propigídio com forte pontuação na metade anterior e com poucos pontos sobre as margens laterais e posterior (Fig. 27); região posterior com uma elevação transversal. Pigídio com pontuação variável.

Comentários: Estria lateral da quilha prosternal pode estar incompleta. A estria subumeral interna pode estar presente; a $2^{\mathrm{a}}$ estria dorsal pode ser completa ou apenas indicada na base dos élitros. Pigídio geralmente com ampla área lisa no disco. Maiores informações taxonômicas, biológicas e de distribuição geográfica sobre as espécies que ocorrem no Brasil são encontradas em LeIvas et al. (2012a)

Distribuição geográfica no Brasil: Amazonas e Pará. Fase de decomposição: final (Fig. 1).

\section{DISCUSSÃO}

Das espécies estudadas, foram encontrados registros para todos os estados das regiões Sul e Sudeste, enquanto no Centro-Oeste foram verificadas ocorrências somente para o Distrito Federal e Mato Grosso. Dentre os estados do Nordeste, há ocorrência no Ceará, Bahia, Maranhão, Pernambuco e Piaú e, para a região Norte, apenas Roraima e Tocantins não têm dados. Contudo, a ausência de dados para grande parte dos estados brasileiros pode ser reflexo de falta de inventários faunísticos regionais, da deficiência de coletas, coleções, publicações e de identificação acurada nos acervos entomológicos.

A maioria dos táxons elencados neste estudo difere dos apresentados por Aballay et al. (2013), em uma compilação dos histerídeos associados à carcaça na Argentina. Nesse estudo foi observado espécies de Carcinops Marseul, 1855, Xerosaprinus Wenzel, 1962, 


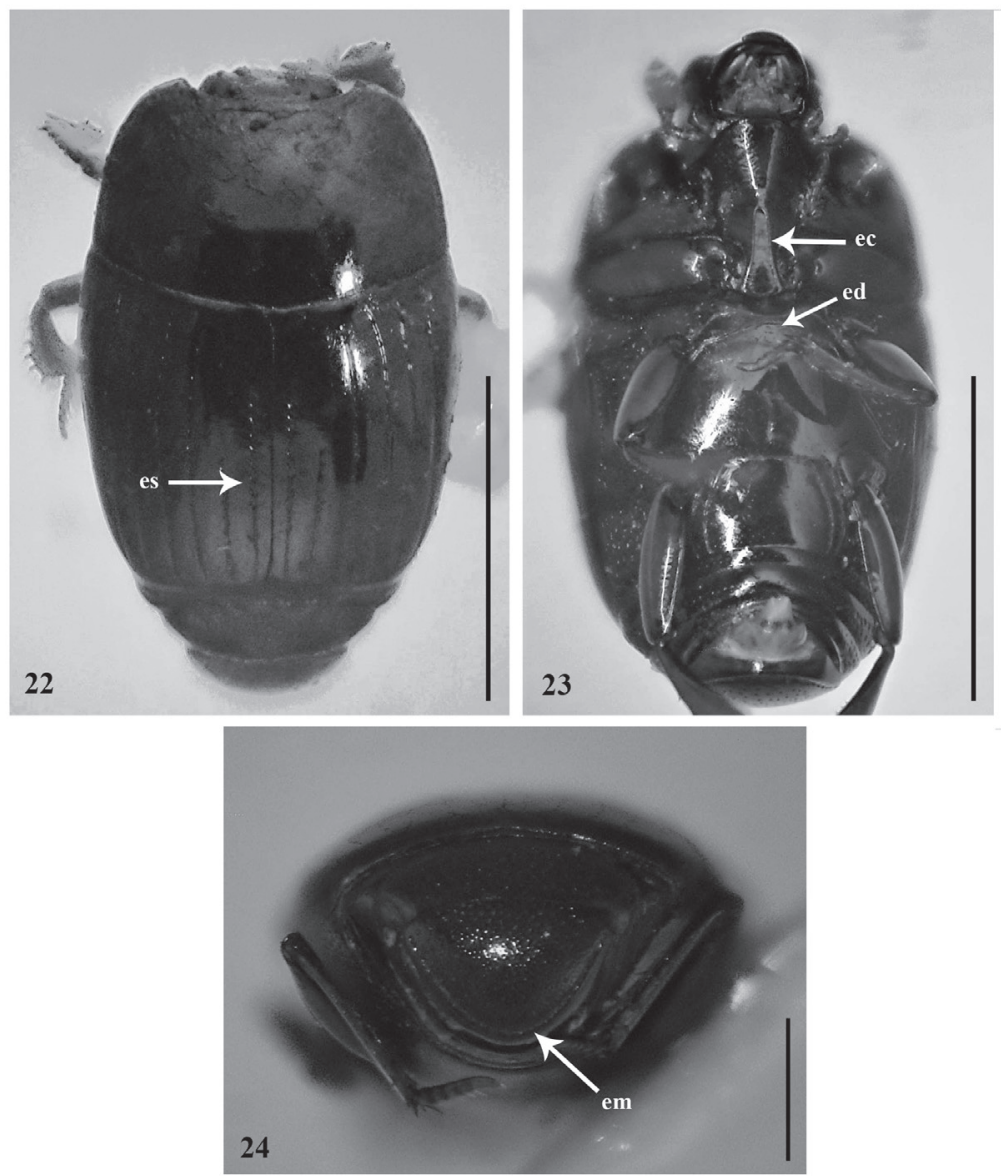

Figs 22-24. Operclipygus subterraneus Caterino \& Tishekin, 2013: 22, vista dorsal, estria sutural dos élitros (es); 23, vista ventral, estria discal da quilha prosternal (ed), quilha prosternal com estria carenal triangular (ec); 24, vista posterior, pigídio, estria marginal (em). Escalas 22, 23: $1 \mathrm{~mm}$; 24: $0,5 \mathrm{~mm}$.
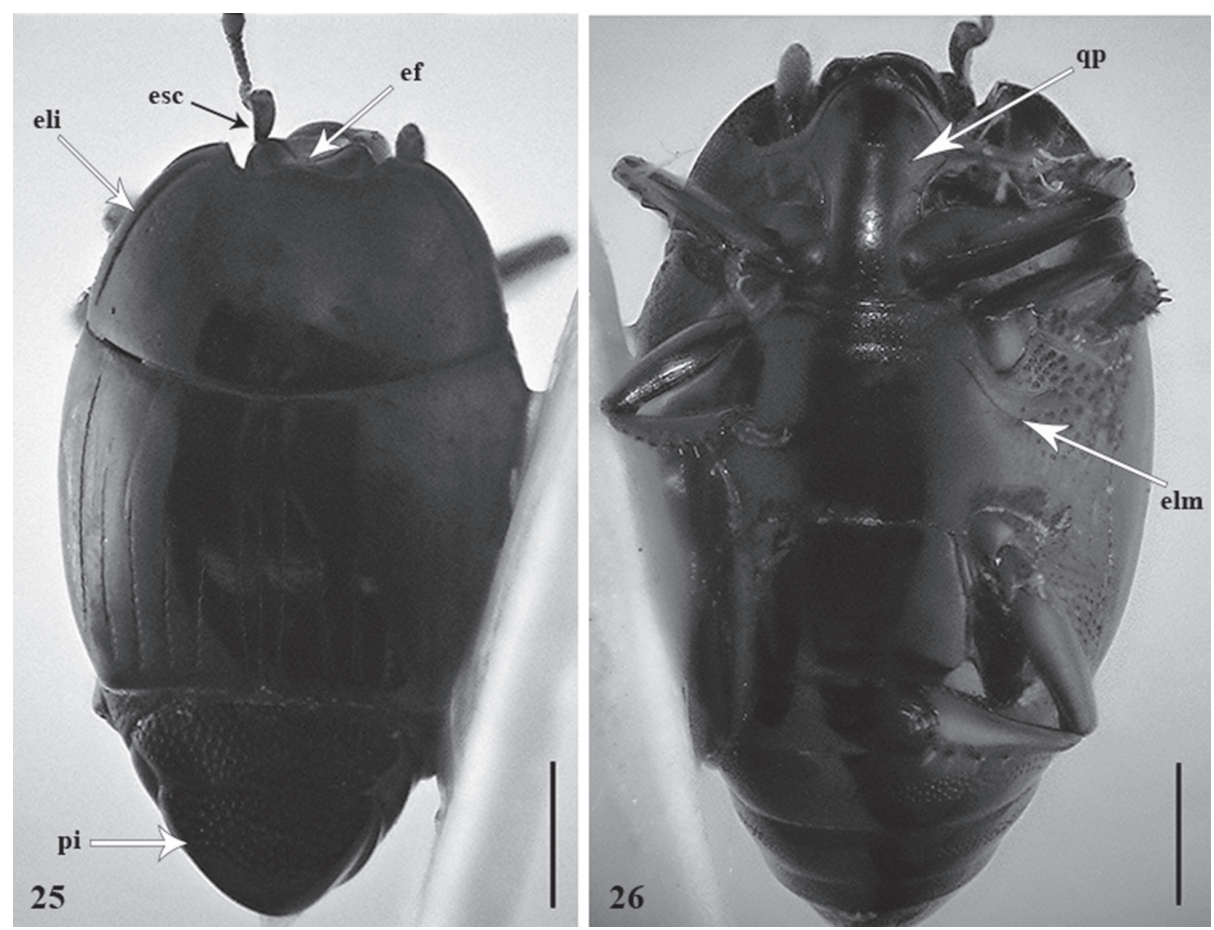

Figs 25, 26. Phelister sanguinipennis Marseul, 1853: 25, vista dorsal, escapo (esc), estria frontal (ef), estria lateral interna do pronoto (eli), pigídio (pi); 26, vista ventral, quilha prosternal (qp), estria lateral metasternal (elm). Escalas: $1 \mathrm{~mm}$. 
Hololepta Paykull,1811, Phelister Marseul, 1854 e Euspilotus Lewis, 1907, sendo que somente os dois últimos foram citados em trabalhos forenses no Brasil e Euspilotus azureus foi a única espécie em comum para os dois países. A ocorrência desta espécie no Brasil abrange apenas quatro estados e pode estar subestimada pela falta de pesquisas direcionadas, uma vez que apresenta uma ampla distribuição na América do Sul (Argentina, Brasil, Guiana Francesa, Suriname e Venezuela) (MAzur, 2011; Degallier et al., 2012). O número de espécies associadas a carcaças na Argentina (16) foi maior que no Brasil (9), o que difere do esperado, devido à quantidade de biomas e ao tamanho do território brasileiro em comparação com o argentino. Tal fato sugere que a carência de coletas é o maior problema para o conhecimento da fauna necrófila no Brasil.
A ordem que os insetos chegam na carcaça pode apresentar um padrão de sucessão, que constitui uma das abordagens para se o calcular o IPM através do vestígio entomológico (BAJERLeIN et al., 2011). Segundo KovariK \& CATERINo (2001), a maioria dos histerídeos é associada às fases iniciais de decomposição, contudo no presente estudo $E$. azureus, $O$. bifoveolatus e $O$. foveola ocorrem em todos os estágios. No presente trabalho, as fases inicial e mediana são as com maior ocorrência de Histeridae, provavelmente devido à alta concentração de imaturos de Diptera, que servem como fonte alimentar para indivíduos da família (Nuorteva, 1970). Omalodes lucidus, P. sanguinipennis e $S$. auritus são exclusivos de uma única fase, inicial, mediana e final, respectivamente. As espécies que ocorrem somente em uma dada fase de decomposição podem auxiliar na estimativa do tempo de exposição do cadáver à ação
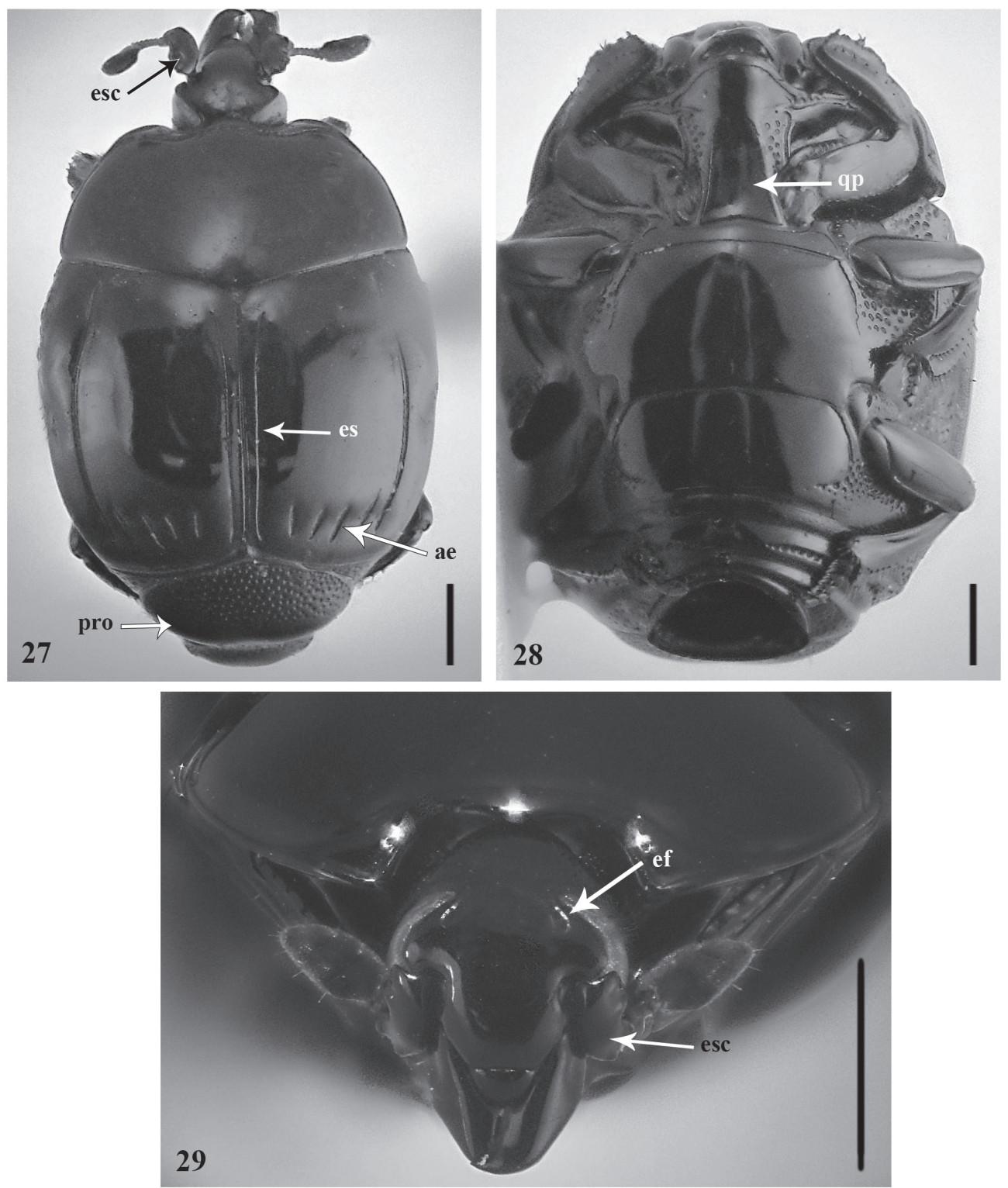

Figs 27-29. Scapomegas auritus Marseul, 1855: 27, vista dorsal, escapo (esc), estria sutural dos élitros (es), ápice dos élitros (ae), propigídio (pro); 28, vista ventral, quilha prosternal (qp); 29, vista frontal, cabeça, estria frontal (ef), escapo da antena (esc). Escalas: $1 \mathrm{~mm}$. 
dos insetos (Kreitlow, 2010). Por isso, vale ressaltar a importância de serem realizados mais estudos sobre sucessão enfocando Histeridae, destacando o momento da ocorrência e permanência das espécies na carcaça.

Besouros predadores normalmente não são considerados nas estimativas de IPM, contudo BAJERLEIN et al. (2011) afirmaram que os predadores podem estar sendo negligenciados por falta de estudos. Apesar de haver uma nova tendência que utiliza o desenvolvimento dos imaturos predadores somado ao tempo que o adulto leva para chegar à carcaça (Maria Fernanda da Cruz Caneparo, com. pess.) ainda são necessários mais estudos incluindo chaves de identificação, biologia e comportamento de adultos e imaturos de interesse para o Brasil. Além disso, estudos de sucessão e atratividade química, somados a coletas em áreas pouco estudadas se tornam ferramentas complementares importantes para a compreensão do papel dessas espécies de Histeridae e sua aplicação na entomologia médico-legal.

Agradecimentos. Ao Dr. Daniel Pessoa de Moura pelo auxílio na confecção das pranchas e sugestões, ao Dr. Júlio César de Moura Leite e aos dois revisores anônimos pela revisão do manuscrito. À CAPES - Coordenação de Aperfeiçoamento Pessoal de Nível Superior pela bolsa de doutorado (MFCC, 1253615/2013) e pós-doutorado (FTW L, Projeto: PNPD20132816 - PNPD - UFMT/ecologia e conservação da biodiversidade) e CNPq pela bolsa de produtividade em pesquisa (LMA, 306772/2006-0). Esta é a contribuição no. 1928 do Departamento de Zoologia, Universidade Federal do Paraná.

\section{REFERÊNCIAS BIBLIOGRÁFICAS}

Aballay, F. H.; Arriagada, G.; Flores, G. E. \& Centeno, N. D. 2013. An illustrated key to and diagnoses of the species of Histerie (Coleoptera) associated with decaying carcasses in Argentina. ZooKeys 261:61-84.

Almeida, L. M. \& Mise, K. M. 2009. Diagnosis and key of the main families of South American Coleoptera of forensic importance. Revista Brasileira de Entomologia 53(2):227-244.

ArCher, M. S.; Bassed, R. B.; Briggs, C. A. \& Lynch, M. J. 2005. Social isolation and delayed discovery of bodies in houses: The value of forensic pathology, anthropology, odontology and entomology in the medico-legal investigation. Forensic Science International 151:259-265.

Arriagada, G. 1986. Histéridos chilenos (Coleoptera: Histeridae). Primeira parte. Revista Chilena de Entomología 14:71-80.

BaJerlein, D.; MATUSZEWSKI, S. \& KonWERSKI, S. 2011. Insect succession on carrion: seasonality, habitat preference and residency of histerid beetles (Coleoptera: Histeridae) visiting pig carrion exposed in various Forests (Western Poland). Polish Journal of Ecology 59(4):787-797.

BoRNEMISSZA, G. F. 1957. An analysis of arthropod succession in carrion and the effect of its decomposition on the soil fauna. Australian Journal of Zoology 5:1-2.

Caneparo, M. F. C.; Corrêa, R. C.; Mise, K. M. \& Almeida, L. M. 2012. Entomologia médico-legal. Estudos de Biologia: Ambiente Diversidade 34:215-223.

Carvalho, L. M. L. \& Linhares, A. X. 2001. Seasonality of insect succession and pig carcass decomposition in a natural forest area in Southeastern Brazil. Journal of Forensic Science 46(3):604-608.

Carvalho, L. M. L.; Thyssen, P. J.; Linhares, A. X. \& Palhares, F. A. B. 2000. A checklist of arthropods associated with pig carrion and human corpses in Southeartern Brazil. Memórias do Instituto Oswaldo Cruz 95(1):135-138.

Caterino, M. S. 1999a. The taxonomy and phylogenetics of the Coenosus Group of Hister Linnaeus (Coleoptera: Histetridae). University of California Publication in Entomology 119:1-75. 1999b. Taxonomy and phylogeny of the Hister servus group (Coleoptera: Histeridade): a Neotropical radiation. Systematic Entomology 24:351-376.

2002. Revision of the Hister militaris group (Coleoptera: Histeridae). Entomological Society of America 95(3):323-334.

Caterino, M. S. \& Tishechkin, A. L. 2013. A systematic revision of Operclipygus Marseul (Coleoptera, Histeridae, Exosternini). Zookeys 271:1-401.

Catts, E. P. \& Goff, M. L. 1992. Forensic entomology in legal investigations. Annual Review of Entomology 37:253-272.

CorrêA, R. C.; Moura, D. P.; Leivas, F. W. T. \& Almeida, L. M. 2012. Operclipygus hospes (Lewis) (Coleoptera, Histeridae): a beetle of potential forensic importance for burried bodies. Neotropical Entomology 41(3):256-257.

Costa, C. 2000. Estado de conocimiento de los Coleoptera Neotropicales. In: Martín-Piera, F.; Morrone, J. J. \& Melic, A. eds. Hacia un proyecto CYTED para el inventario y estimación de la diversidad entomológica en Iberoamérica PrIBES 1. Zaragoza, Sociedad Entomológica Aragonesa, p. 99-114.

Degallier, N.; Arriagada, G.; KanaAr, P.; Moura, D. P.; Tisheckin, A. K.; Caterino, M. S. \& Warnes, W. B. 2012. Coleoptera Histeridae Guyane. VII. Compléments au catalogue avec des données sur la faune du Surinam et une contribution à la connaissance des Saprininae. In: Coléoptères de Guyane. Paris, ACOREP, p. 33-52.

Goff, M. L. 1991. Comparison of insect species associated with decomposing remains recovered inside dwellings and outdoors on the island of Oahu, Hawaii. Journal of Forensic Sciences 36(3):748-753.

KovariK, P. W. \& CATERINo, M. S. 2001. Histeridae. In: ARnETt, R.H. \& Thomas, M.C. eds. American Beetles Archostemata, Myxophaga, Adephaga, Polyphaga: Staphyliniformia. Boca Raton, CRC Press. v.1, p. 212-227.

KreitLOW, K. L. T. 2010. Insect succession in a natural environment. In: Byrd. J. H. \& CASTNER, J. L. eds. Forensic Entomology: The Utility of Arthropods in Legal Investigations. Boca Raton, CRC Press, p. 251-269.

Kulshrestha, P. \& Satpathy, D. K. 2001. Use of beetles in forensic entomology. Forensic Science Internacional 120:15-17.

Leivas, F. W. T.; Bicho, C. L.; Degallier, N. \& Moura, D. P. 2012a. Revision of the genus Scapomegas Lacordaire, 1854. (Coleoptera: Histeridae: Omalodini). Zootaxa 3482:33-46.

Leivas, F. W. T.; Mise, K. M.; Almeida, L. M.; Macari, B. P. \& Gomy, Y. 2012b. New species and key of Aeletes Horn (Coleoptera: Histeridae: Abraeinae) from Brazil. Zootaxa 3175:63-68.

Leivas, F. W. T.; Grossi, P. C. \& Almeida, L. M. 2013. Histerid beetles (Staphyliniformia: Coleoptera: Histeridae) from Campos Gerais, Paraná, Brazil. Biota Neotropica 13(2):196-204.

Leivas, F. W. T.; Bicho, C. L. \& Almeida, L. M. 2015. Cladistic analylis of Omalodini Kryzhanovskij (Coleoptera: Histeridae: Histerinae). Systematic Entomology 40:433-455.

Lord, W. D. \& Stevenson, J. R. 1986. Directory of forensic entomologists. 2ed. Washington, Armed Forces Pest Management Board. 42p.

Luederwaldt, G. 1911. Os insetos necrophagos paulistas. Revista do Museu Paulista 8:414-433.

Marinoni, R. C. 2001. Os grupos tróficos de Coleoptera. Revista Brasileira de Zoologia 18(1):205-224.

MaYer, A. C. G. \& VASCOncelos, S. D. 2013. Necrophagous beetles associated with carcasses in a semi-arid environment in Northeastern Brazil: implications for forensic entomology. Forensic Science International 226:41-45.

Mazur, S. 2001. Review of the Histeridae (Coleoptera) of Mexico. Dugesiana 8(2):17-66.

2011. A Concise catalogue of the Histeridae: (Insecta: Coleoptera). Warsaw, University of Life Sciences - SGGW Press. 332p.

MÈGNIN, J. 1894. La faune des cadavres: application de l'entomologie à la medecine legale. Encyclopedie Scientifique des Aides-Memoire. Paris, Masson et Gauthiers-Villars. 214p.

Mise, K. M.; Almeida, L. M. \& Moura, M. O. 2007. Levantamento da fauna de Coleoptera que habita a carcaça de Sus scrofa L., em Curitiba, Paraná. Revista Brasileira de Entomologia 51(3):358-368. 
Mise, K. M.; Souza, A. S. B.; Campos, C. M.; Keppler, R. L. F. \& AlmeIDA, L. M. 2010. Coleoptera associated with pig carcass exposed in a forest reserve, Manaus, Amazonas, Brazil. Biota Neotropica 10(1):322-324.

Monteiro-Filho, E. L. A. \& Peneireiro, J. L. 1987. Estudo de decomposição e sucessão sobre uma carcaça animal numa área do estado de São Paulo, Brasil. Revista Brasileira de Biologia 47(3):289-295.

NuORTEVA, P. 1970. Histerid beetles as predators of blowflies (Diptera, Calliphoridae) in Finland. Annales Zoologici Fennici 7:195-198.

Oliveira-Costa, J. 2008. Entomologia forense: quando os insetos são vestígios. Campinas, Millennium. 257p.
Payne, J. A. 1965. A summer carrion study of the baby pig Sus scrofa Linnaeus. Ecology 46(5):592-602.

Silva, R. C. S. \& SAntos, W. E. 2012. Fauna de Coleoptera associada a carcaças de coelhos expostas em uma área urbana no sul do Brasil. EmtomoBrasilis 5(3):185-189.

SOUZA, A. S. B.; KIRST, F. D. \& KRÜGER, R. F. 2008. Insects of forensic importance from Rio Grande do Sul state in Southern Brazil. Revista Brasileira de Entomologia 52(4):641-646.

ZHANG. Z. Q. 2011. Animal biodiversity: an introduction to higher-level classification and taxonomic richness. Zootaxa 3148:7-12. 